\title{
Correction to: Social Media for Tobacco Smoking Cessation Intervention: a Review of the Literature
}

\section{Johannes Thrul ${ }^{1} \cdot$ Kayla N. Tormohlen ${ }^{1} \cdot$ Meredith C. Meacham ${ }^{2}$}

Published online: 10 May 2019

(C) Springer Nature Switzerland AG 2019

\section{Correction to: Current Addiction Reports} https://doi.org/10.1007/s40429-019-00246-2

The original version of this article unfortunately contained a mistake. The sentence "...studies one of which used WhatsApp in addition to Facebook, and two studies used Twitter, and one other used WhatsApp in addition to Facebook. QuitNet, an online...” should be “... studies, one of which used WhatsApp in addition to Facebook. Two studies used Twitter. QuitNet, an online...".

The original version has been corrected.

Publisher's Note Springer Nature remains neutral with regard to jurisdictional claims in published maps and institutional affiliations.

The online version of the original article can be found at https://oi.org/ 10.1007/s40429-019-00246-2

Johannes Thrul jthrul@jhu.edu

1 Department of Mental Health, Johns Hopkins Bloomberg School of Public Health, 624 N Broadway, Baltimore, MD 21205, USA

2 Department of Psychiatry and Weill Institute for Neurosciences, University of California San Francisco, 401 Parnassus Ave., San Francisco, CA 94143, USA 